\title{
De un boom al otro: sobre realismos mágicos y gastronomías salvajes en Latinoamérica
}

\author{
Julio Hevia Garrido Lecca \\ (Universidad de Lima)
}

Recibido: 31/3/2013

Aceptado: $2 / 5 / 2013$

\begin{abstract}
Resumen: Tomando la lectura de Alejo Carpentier sobre lo real maravilloso en la narrativa latinoamericana y las apreciaciones que J. Goytisolo nos alcanza de la ensayística interdisciplinaria francesa, el artículo pone a prueba los alcances y limitaciones de la actual resonancia que tiene la gastronomía peruana. Ciertas prácticas orales cotidianas, como el comer y el beber, son consideradas en función de los diferentes capitales culturales que las envuelven. Entre tanto, caracteres etnográficos, tópicos microsociales y apelaciones literarias contribuyen a desmontar la colonización con que una mirada primermundista permea el marketing mediático en este orden de cosas.
\end{abstract}

Palabras clave: Realismo mágico / surrealismo / colonización / distancia / estereotipos / oralidad

\section{From one boom to another: about magic realism and wild gastronomy}

Summary: Taking into account the reading of Alejo Carpentier on the wonderful of the Latin-American narrative and comparing it with the appreciations of J. Goytisolo in relation to the interdisciplinary of the French essay, the article describes the scopes and limitations of the impact that the Peruvian gastronomy currently boosts worldwide. Some features of customary practice, such as drink and eat, are shown considering the different cultural capitals involved. Meanwhile, the ethnographic features, micro-social topics and the literary appellation allow detecting the colonization shade that a first world point of view in the marketing media has on the order of things.

Keywords: Magic realism / surrealism / colonization / distance / stereotypes / orality 


\section{Realismos cercanos y surrealismos remotos}

fin de diferenciar el estatu-
to de la imagen cinemato-
gráfica en el Tercer Mundo, y el de Latinoamérica en particular, F. Jameson recupera la ironía tiempo atrás levantada por Alejo Carpentier, de que el surrealismo francés, en su promocionada búsqueda de eventos insólitos, no pasó de ser un intento infructuoso de acceder a aquello que un cotidiano pletórico y desbordante proveía sin esfuerzo Hispanoamérica (Jameson 1995: 145). Hoy concluiríamos que si algo había de «maravilloso» $\mathrm{y}$ «novedoso» en lo real de aquella narrativa latinoamericana, este se encontraba en la propia visión de una crítica europea especializada, vale decir, en la apreciación glorificada que de aquella corriente hizo circular un mercado literario ávido de exotismos periféricos.

Más reciente es la acotación de J. Goytisolo cuando, en una línea complementaria al señalamiento anterior, advierte que en el mismo momento en que el llamado «Boom latinoamericano» hacía eclosión en el mundo narrativo, en Francia se gestaban las condiciones básicas para la puesta en marcha de un pensamiento claramente cuestionador de las matrices interpretativas imperantes, de preferencia materializado en una serie de ensayos especialmente afines a sofisticadas deconstrucciones y apuestas interdisciplinares (Goytisolo 2007: 323-325).
Goytisolo pensaba pues en un efecto de ida y vuelta, es decir, que allí donde la narrativa primermundista no encontraba más fuentes de las que abrevar, el novelista latinoamericano trasladaba, con humor y naturalidad, al ámbito de la ficción escritural lo que su mismo entorno le proporcionaba. Invocando a Max Ernst se diría que el «boom latinoamericano» operó de modo análogo al denominado collage pictórico: suerte de juntura de dos dimensiones, en apariencia inconciliables, que van a armonizar sobre un plano que, al menos en principio, no combina con ellas (Clifford 1998: 132).

A la inversa, condiciones para cristalizar atrevimientos teóricos como los que en su momento representara, por ejemplo, la ola vanguardista aglutinada en torno a la revista parisina Tel Quel, difícilmente podrían haberse dado en Latinoamérica, región capturada por las tenazas de un poder neocolonial que, además de económico, supo enraizarse ideológicamente. ¿Ensayistas de unas teorías en ruinas por allá, frente a narradores de un cotidiano más cercano y, por ello mismo, requerido de intérpretes acá? En todo caso se sabe que en el Tercer Mundo los novelistas se erigieron con frecuencia en grandes articuladores, cuando no en voceros visibles, del sentir mayoritario. En el Perú, por ejemplo, Vargas Llosa pretendió saltar de la orilla literaria a la arena política, aunque su intento constituyó, paradójicamente, un error fructífero o un desliz favorable a su propia obra escrita. 
Procuremos otro indicador de esa disparidad, nunca ajena a los referentes culturales que la gestan y a los que sirven. Así pues, se ha postulado que la obra de Baudrillard trazó un giro notable desde que el polémico autor empezó a aficionarse a la práctica fotográfica. Fue justamente reflexionando sobre los vaivenes profesionales de esa práctica, y a propósito de las temáticas que merecen los mayores reconocimientos en prestigiados certámenes internacionales, que Baudrillard denunciaba un fuerte énfasis en la celebración de lo excéntrico, operación nunca del todo desprovista de tintes paternalistas. Obvio es acotar que desde aquella sensibilidad el sector culto del planeta se rinde ante los extremos en los que sobreviven las grandes mayorías de unas realidades en desarrollo (Baudrillard 1990: 158-63). Acotaba Baudrillard que lo que más valora el fotógrafo del primer mundo, en su infatigable discurrir, es la singular dignidad con que suele posar el buen salvaje, la solemnidad ritual que aporta el indígena, en fin, el aura que encarnan y recuperan los sempiternos olvidados ante el visor de la cámara. ¿Tránsito y conversión del migrante bajo sospecha allá, hacia una adhesión insospechadamente desprendida acá por un nativo fascinante? ¿Poscolonialismo agazapado en las tendencias de unas modas, hoy llamadas étnicas?

Distintos e incluso autónomos, los paisajes que traemos a colación conservan un invariante, iconográfico o imaginario, que hay que resaltar.
Nos referimos al hecho de que tanto Carpentier como Goytisolo y el mismo Baudrillard rodean y enfocan un terreno que es el de las diferencias interculturales. Diferencias que en su extremo van a operar como soportes de unas enunciaciones política y teleológicamente interesadas, acotaría Derrida, o que en su permanente escudriñar, y siempre afines a las violencias de los guetos citadinos, arribarán a lo que Wacquant calificó como criminalización de la pobreza. Así, de la confrontación de los particulares devenires entre una y otra historia, de la coexistencia tensa entre miradas oficiales y registros menos pomposos, se puede concluir que lo que se presenta como irreductible en el terreno, siempre sinuoso, del quehacer etnográfico y torna inasible la diversidad del espectro cultural en que aquel se despliega, es que lo considerado valioso, al inscribirse en un ámbito ajeno, es, por necesidad y hasta nuevo aviso, distante e incomprensible.

Nótese el valor que esa misma distancia tiene como exigencia metodológica para que los fenómenos explorados no sufran alteración alguna, para que permanezcan impolutos o virginales; recuérdese por añadidura que tal distancia se ha constituido como un protector técnico contra las contaminaciones del afecto y se ha erigido en condición sine qua non para el mantenimiento de una modernidad científica fóbicamente neutra. A distancia también se encuentran, cabe enfatizarlo también, las jaulas en las que 
se atrapa a los entes domesticables y, en otro sentido, las vitrinas a las que pocos van a acceder y que muchos, en la siempre acomodaticia nivelación aspiracional, deberán envidiar.

\section{Lo oral siempre es ahora}

Vayamos al grano: es preciso dar cuenta de que el comer y el beber no son directamente afines, en su valoración general, al alcance aristocrático que la mirada y el audio, como sentidos de la distancia, suelen desplegar. El comer y el beber se encuentran prioritariamente involucrados, por su misma práctica y a propósito de la domesticación social que consolidan, al tacto y al gusto, órganos menos auspiciosos y más afines al plano de la invisibilidad diaria $\mathrm{o}$, por decir lo menos, a una visibilidad carente de prestigio. Desde el terreno rutinario en que se encuentran claramente implicados, el comer y el beber nos desafían no sin cierta ironía, tanto por el rol decisivo que desempeñan en el plano fisiológico, como por su calidad de marco cultural encargado de juzgar o sancionar toda performance social, tal cual ha probado sobradamente N. Elias.

Urge llamar la atención sobre el lado básicamente oral que separa a los potajes nobles de los nutrientes plebeyos, pero igualmente interesará destacar cuánto, en la misma puesta en acto de las prácticas comestibles, lo suntuosamente accesorio se imbrica al reino de las necesidades alimenticias.
Así, entre la supuesta polarización de los modos más formalizados que unas cenas de élite ponen en acto y las ingestiones que a campo abierto despliega la cultura pop, habrá todo un oleaje de lecturas y consideraciones agolpadas en series sucesivas, un amplio espectro de pautas y estilos, de filtros e intermediaciones, de préstamos recíprocos y mestizajes varios, como suele corroborarse en el caso de cualquier acontecimiento comunicativo que se constituya en objeto de análisis e interpretación.

Las propias prácticas orales al tornarse contiguas, ya lo hemos advertido, al reino de las urgencias biológicas y sus intereses corporales o por el hecho de verse recostadas hacia el diámetro de unos ímpetus básicos, suelen figurar en una línea adecuadamente oblicua y por demás ajena a los más grandes y refinados logros culturales. No en vano el psicoanálisis acota la etapa oral en un estadio inicial que atestigua la fusión y confusión entre necesidades y deseos o entre instintos y pulsiones. La zona oral, en tanto escenario de emergencia privilegiado para un erotismo naciente, sería entonces el punto de anclaje o el mejor pretexto para un deslizamiento que posibilita, en clave libidinal, el paso de los procesos primarios a los procesos secundarios. Sustancialmente análoga es la apreciación que de la misma dimensión oral efectúan distintas entradas antropológicas, polarizando un régimen inmediato y gozoso o ajeno a desarrollismos, respecto a un canon 
escritural que trasciende el discurrir boca-a-boca de las tradiciones milenarias y el del secreto a voces de los relatos míticos, para arrojarnos de una vez por todas al mundo de la memoria sistemática, al inventario acumulable en formatos tecnológicos cada vez más sofisticados.

\section{El speech de lo kitsch}

Hemos hecho mención entonces de dos estrategias, la freudiana y la antropológica, que lo académico habría implementado y desde las que se percibe una cierta declinación valorativa de la fenomenología de la oralidad, sea desde el encuadre freudiano que coloca las pulsiones orales en el inicio del itinerario del deseo y que no en vano lo cierra, evolutivamente digamos, con la llamada genitalidad adulta; sea en función de una perspectiva cultural diseñada por la etnografía moderna imperante, a partir de la cual la oralidad, volcada al terreno de la charla $\mathrm{y}$ al de las destrezas verbales colectivas, se ve atenazada por el régimen de la escritura y sus correspondientes soportes, entendiendo a esta última como sinónimo de progreso, como la maquinaria que habrá de permitir el quiebre y la superación de un primitivismo al acecho. Interesante resulta rescatar el llamado de Carlos Fuentes cuando concluye que, con cada anciano migrante que fallece en Estados Unidos, todo un saber se pierde con él, toda una cultura testimonial desfalle- ce, dados los requerimientos productivistas que la escena capitalista implementa y exige (Fuentes 1992: 378).

Notemos por añadidura que los estudios del llamado estilo kitsch suelen remitir su emergencia a goces sensoriales gratuitamente convocados y arbitrariamente multiplicados; vinculan su aparición y multiplicación a auditorios poco adiestrados a la espera o especialmente emparentados con una ética de corto aliento. Atravesados por el estigma del horror al vacío, tales enfoques sobre la escenografía kitsch levantan diagnósticos claramente lapidarios sobre lo que hay de grotesco en el fenómeno examinado, condenando e inhabilitando así a todo lo que se atreva a alterar el orden legítimo, a todo lo que no se ha tramitado a tiempo ni cuenta con el visado correspondiente (Calinescu 2003: 57).

Así pues, entre el potaje peruano popular y aquel otro que reclama, orgulloso y rimbombante, su pertenencia al terreno de una gastronomía novo-andina hay, en sus extremos, la apelación a una paleta de colores que, en su versión cotidiana y cual prolegómeno ilustrativo del platillo a devorar incluye - pensemos en el paradigmático cebiche- los tonos rosas y lilas de las cebollas, los matices moros y anaranjados del camote, los rojos y amarillos de los ajíes, la misma palidez de los peces troceados, mientras que en la propuesta gourmet, visualmente sofisticada y marketeramente innovadora, el espectro cromático opera cual su- 
plemento estetizante, toque de glamour o abstracción minimalista, ensayando combinatorias visuales sin precedentes sobre el plato o aislando pequeñas unidades, a manera de islotes, entre los que habría de naufragar la degustación más contenidamente cool del comensal cultivado: en vez del diálogo entre lo visible y lo legible, tal cual se constata en los cuadros de Magritte (Foucault 1993), atestiguamos la inserción de lo legible/visible en el hábitat de lo comestible, en el diámetro semidesértico del propio plato.

Insistimos entonces en lo obvio: no hay modo alguno de prescindir del concurso que una mirada, rígida o flexible, rigurosa o contemplativa, suele prestar a todo ejercicio analítico. Dicho de otro modo, además de reconocer lo que miramos, es relevante el cómo y desde dónde lo hacemos. Fundamental es preguntarse entonces, desde una intersubjetividad que no se limite a lo meramente personal, por lo que mira el otro en uno, por lo que fabrica y confirma el otro cuando nos ve; en fin, indagar por lo que aquel otro descubre a partir de una matriz funcionalista siempre requerida de familiarizarse con lo extraño o de apropiarse de lo ajeno (Clifford 1998: 167). Lo de menos es entonces poseer unos capitales culturales (Bourdieu 1991: 7890) pues, de lo que se trata es de distinguir cuán poseídos estamos por ellos, cuán poseídos vamos a seguir estando por unos capitales que, entre costos concretos y beneficios prometidos, nos capitalizan. Borges, por ejemplo, declaró alguna vez que el sitial que le fuera concedido en el panteón de la literatura mundial se debía, más que a sus propios méritos, a su lugar de origen. Si hubiera nacido en Europa, remataba el genial escriba, otro hubiera sido el destino de su obra (Borges 1999: 59).

\section{Pantallas que muestran, pantallas que ocultan}

Así pues, todo lo que se pone de moda es puesto de moda por alguna óptica y en función del estatus que ella destila; todo lo que impera lo hace desde algún canon cuya capacidad compensatoria o consoladora nunca debiéramos desdeñar. He allí, por ejemplo, el espíritu jovial y aventurero con que ciertos visitantes autorizados del primer mundo dan cuenta, en la televisión por cable, de lo que les es ofrecido por sus afanados anfitriones bananeros; las más de las veces, se trata de los platillos que a diario y por doquier se consumen en la zona visitada y con los que se quiere agasajar al ilustre hospedado. Emisión tras emisión, podemos apreciar que la performance del conductor oscila entre el esfuerzo que realiza por no perder la espontaneidad del caso, como quien se acoge a una suerte de imperativo goffmaniano, y un aire open mind telegénicamente actualizado que disuelve y absuelve lo local en nombre de lo global.

Habida cuenta de las variantes espaciales y hábitos posturales que toda 
práctica social anima y hacia la que nos conmina, tendríamos que preguntarnos por la consideración y respeto que debieran merecer, en los formatos mediáticos aludidos, los juegos proxémicos consignados por E. T. Hall en sus periplos etnográficos (Hall 1971). O interrogarse, a propósito del clima conversacional recreado y por el destino, mil veces mentado, de la función fática, que un Jakobson recuperara de Malinowski (Jakobson 1975), a fin de incluir en sus modelos comunicativos todo aquello que parecía escapar a la ideología utilitarista del viejo continente: ¿Zonas ciegas al colonizador? ¿Intersticios de la utopía omnisapiente en la que ha reposado el tribunal de la razón occidental? En todo caso, nunca está de más insistir en el hecho de que la globalización, en vez de borrar las diferencias locales, las garantizan y naturalizan por repetición, las recrean y saturan sea con los vaivenes turísticos que democráticamente se programan de allá para acá; sea mediante unas incontenibles pujanzas migratorias perpetradas de acá para allá.

\section{Picos, piqueos y picantes}

$\mathrm{Si}$, como sentenció Vargas Llosa, hay en los personajes y en las fuerzas convocadas por la obra de Arguedas una dimensión ceremonial inequívoca, una ritualidad que atraviesa toda actividad diaria y propende a una suerte de realización comunitaria (Vargas Llosa 1996: 274-275), valdría la pena explorar también nuestra propia dramaturgia del día a día, antes de confirmar unos prejuicios etnocentristas cuyo poder suele nutrirse de nuestra ignorancia para mejor ratificar el orden estratificador al cual sirven. En el Perú, por ejemplo, se pueden distinguir una serie de prácticas y no pocas sentencias, condensadas todas en torno a la figura del pico que van a generar, de modo exponencial, efectos de sentido y posibilidades situacionales entre las que cabe incluir beligerancias verbales - ponerse de pico a pico-, guiños amorosos -darse un piquito-, reacciones desmedidas en medio de una competencia - picarse - generación de climas tensos - picantes - o aprovechamientos del descuido ajeno - meter un picotón-.

Interesa, sin embargo, resaltar dos expresiones: la que indica que hay que tomar a pico y la que demanda, cuando el hambre cunde, un consumo grupal del llamado piqueo. Si de tomar a pico se trata, no hay más contacto con el alcohol que el establecido entre el pico de la botella y el pico de los bebedores, entre una y otra boca, entre uno y otro agujero. Sucesiva e infatigablemente, todas las veces que sea necesario, ese tomara-pico procederá hasta que la ebriedad se apodere de los cuerpos y enrarezca los temas, confundiendo allí las palabras y las cosas. Virando el eje de lo bebible a lo comestible, la degustación de un piqueo convoca en simultáneo a todos los presentes para que, trinches en mano y con inusual celeridad, se 
disputen hasta los últimos bocados: en tal trance y según reza la sentencia de Cortázar, el que piensa, pierde.

Según puede apreciarse, se trata de modalidades muy directas, poco elaboradas quizá, de departir y repartir, de repartir y compartir, pero también de pugnar y tensar, de desafiar y competir (Hevia 2008: 130-132). Reina en tales contextos un clima lúdico, de protagonismos gregarios y en el que la comida y la bebida operan cual vasos comunicantes, dejando de lado el ego de cada cual y a sus clásicas funciones de aislantes personalizados, como lo entendía Klossowski. Elevados tales rituales al rango de credenciales inviolables, lo natural es que resulten, inicialmente al menos, refractarios a las equivalencias que el investigador foráneo persigue incesante e inconsciente. Recordemos por cierto con Baudrillard, que el inconsciente freudiano solo sabe de interpretaciones, procedimiento que pretende domesticar los encantos con que unas reglas inasibles se ponen en juego y con que unos mestizajes, que datan de la noche de los tiempos, le dan la espalda a las leyes consuetudinarias (Baudrillard 1981: 55-60).

\section{Estereotipos y tipos en estéreo}

Veamos qué estereotipos pesan sobre nuestras espaldas en los tiempos actuales y qué tan saludable resulta que los entendamos en un país como el Perú, cual si fueran desafíos a confron- tar o conflictos a salvar. Infantilizadas de distintas maneras, por dispositivos ideológicos y etnocentrismos perennes, nuestras situaciones y sus habitantes no son solo caracterizadas como superficies en las que todo parece faltar, sino, complementaria y paradójicamente, como existencias históricas $\mathrm{y}$ articulaciones sociales proclives al exceso y al desborde continuo, sempiternamente tentadas por el desorden. No pocas veces se habla de una sociedad anómica, desprovista de reglas e institucionalidad que desconcierta al visitante porque, tal cual se ha visto, cuestiona en su práctica misma a una individualidad libre y convenientemente autocontrolada, individualidad que los discursos canónicos entienden como instancia fundante del orden social o valor per se de la modernidad.

Inversamente, entre nosotros, el hecho mismo de comer supondría entonces devorar el alimento entre todos y ante todos, demostrando así que el binomio público/privado y su supuesta superación posmoderna nos sería ajena, ya por reconocérsele como demasiado inserta en otros ciclos y costumbres o porque su tardía coincidencia nada de novedoso aporta a los usos de siempre. Comer es pues comer en comunidad (Canetti 1981: 109-110), de allí que a la juerga descomunal, tipo carnaval o desbande colectivo, habría un paso. Siempre ávidos de carnes y, por lo general, ajenos a la salud corporal y a la calidad de vida, lo antrocéntrico acá sufriría de una cierta nostalgia antro- 
pofágica. La gente come con la mano, se chupa los dedos, se afirma en una especie de sobredosis de carbohidratos no convenientes; los comensales se vengan a escondidas de unos regímenes dietéticos que suponen sacrificios inenarrables o implican abstinencias difícilmente sostenibles. A propósito de tales ímpetus, por estos lares se dice que nos castigamos diariamente $o$ durante los fines de semana con todas las materias comestibles al alcance.

Quizá un afán didáctico nos haga caer, de modo inevitable, en ciertos dualismos; de repente así corremos el riesgo de negar las coexistencias de los gustos más disímiles y las convergencias en toda suerte de elecciones; tal vez parezcamos ajenos a la fiesta de las mixturas y a la celebración de los mestizajes; capturados pues por una «angustia de la influencia» que impidiera darle la bienvenida a esa suerte de laboratorio experimental, hoy en boga, entendido como espacio propicio para todo tipo de afectaciones recíprocas. Nada más lejos de nuestras intenciones, máxime si recordamos, por ejemplo, que en Lima el maridaje entre condimentos nativos y la herencia de la comida china ha producido uno de los encuentros culinarios más armónicos y mejor apreciados internacionalmente.

Recordemos, a propósito de lo anterior, que la consabida distancia entre los de arriba y los de abajo la puede disolver, transitoriamente, el propio trajín del festejo y el relajamiento de unas vigilias en trance de suspensión, o también aquellos apuros que obligan a súbitas degustaciones, esas que instalan al más pintado en el lugar de cualquier hijo de vecino, sobre todo en la realidad del vecino pobre, aglutinando de una vez por todas lo que hubiese de disponible en las bandejas del caso. Tal efecto tanto se precipita en el caso del llamado aeropuerto del ámbito popular limeño (plato pequeño en el que, a como dé lugar, se hace caber el arroz, las papas, los tallarines y alguna salsa que armoniza el insospechado conjunto) como el mejor reconocido bufet, sea por lo universal de su ocurrencia o por el listín de variantes comestibles que ofrece. Otro tanto ocurre con la diversa propuesta marina con la que acá se cuenta y en la que lo recibido y entregado en cada puerto, en cada caleta, en cada cevichería, tiende a reflejarse o a refractarse en el paladar anonadado del expectante comensal. Temperaturas acuáticas, nutrición del pez y, sobre todo, un limón dulce e incomparablemente jugoso protege, cual patrón místico, a un ceviche peruano que, de experimentarse en la madrugada alcanza, por estas tierras, su más alta valoración.

\section{¿Vivir para comer?}

Al interrogarnos ¿será que en el Perú comemos para vivir o no podemos dejar de vivir para comer?, no faltarán, claro está, argumentos para tomar partido por una respuesta que, sobre la marcha, nos instala en el segundo de los 
nichos, territorio próximo a la gula y al placer desmedido, a una lujuria que, poco discreta, nos condenaría a perpetuidad. Tampoco olvidaremos cuánto contribuyen a ese diagnóstico la mayoritaria muestra de casos y experiencias en las que al ciudadano común le resulta materialmente imposible escapar de todos los anzuelos gráficos que, arrasando con la visión, instigan a todo mundo a mimarse con la empanada o a inmolarse con la gaseosa; figuras que, en toda suerte de escenarios citadinos, prometen cenas opíparas o placeres al paso por precios siempre accesibles para todas las posibilidades. Es injusto olvidar, por cierto, que lo más jugoso de las ganancias con que hoy por hoy se benefician las cadenas multinacionales de comida chatarra son recogidas en el tercer mundo: los porcentajes de obesidad últimamente registrados en tales realidades son prueba fehaciente de ello.

Por último, ¿quién ignora que al colmar el hambre de hoy y prevenirse de la escasez futura, gran parte de la gente se somete, sin chistar, a una suerte de brake compulsivamente autoadministrado que remeda y compensa a una merienda hogareña en extinción o persigue, hasta el propio mediodía, al desayuno perdido? Estirando el almuerzo hacia atrás o hacia adelante, el apetito opera como una especie de banda elástica, cual operador topológico susceptible de gratificarse por dosis, con una serie de bocadillos y de postres devenidos golosinas, presentados como tortas o helados. Dependiendo de la óptica asumida, un buen espectro de las reacciones y posiciones ocupadas por el peruano promedio ante los arrestos gastronómicos entretejidos por nuestros chefs más notables, puede tanto entenderse como una resistencia a tal política o cual trabajo de asimilación y acomodación gradual del que cada sector irá extrayendo su tajada, mientras va efectuando las necesarias concesiones (al deseo) y los correspondientes ajustes (al presupuesto). Se trata, no es poca cosa, de sopesar los costos del acceso a la zona VIP del mercado o, en otra clave, de tentar el ingreso, por tardío que resulte, a aquello que Carlos Fuentes calificó como el banquete de Occidente.

\section{Lo que nos brinda el brindis}

Hay que resaltar que el ámbito de la bebida, al menos en el rubro alcohólico, lleva una patente inequívoca en el Perú, aunque en el caso mayoritario la cata de las sustancias retroceda, cual estructura ausente, ante una búsqueda, cada vez más acelerada, de la embriaguez, de la impronta catártica o del sedante catalítico. Reactivos ralentizados o bipolares en el extremo, los peruanos salimos de nuestro letargo cuando campañas inteligentemente orquestadas por un vecino país anunciaron que la identidad del celebérrimo pisco no era, a fin de cuentas, peruana. La réplica, aunque escan- 
dalizada o histriónica, tampoco duró mucho. Total, nada de grave ocurrirá mientras la entrañable cerveza nacional esté adecuadamente protegida de las improntas de la competencia internacional.

Para terminar, y como quien evoca lo mal que puntúan nuestros compatriotas en las encuestas que, a nivel continental, pretenden retratar estados anímicos, predominancias eufóricas o disfóricas entre vecinos, recordemos con Borges que la felicidad no es un estado ni un logro a estabilizar, sino una captura instantánea y esquiva, una racha que tan pronto llega como ya insinúa, caprichosa, su retirada (Borges 1999: 88). Afín a la risa estentórea y opuesta al imperativo telegénico que hoy nos invade (Lipovestky 1995: 136-146), esa felicidad va a recortar, irresponsable, las crisis nuestras de cada día entre charlas sobre comidas y discusiones propiciadas por bebidas siempre bienvenidas. Comer, beber y hablar son entidades inseparables de un complejo mayor, el de una triangulación oral que, entre mares y bares, nos alude y elude, nos ocurre y socorre. Bien decían los estudiosos del grupo humano que la dinámica social recién se instaura con el tres y es desde el tres que se multiplica.

En todo caso, el dilema que abre el boom gastronómico peruano, pujante, promisorio y emprendedor incluye otras aristas a contemplar, lados más ásperos e incluso zonas ciegas. Así pues, estamos hablando de incluir, en la agenda de la discusión, la necesidad de recoger alternativas viables y encontrar soluciones realistas para trabajar la brecha que se abre entre lo que se valora de un lado y lo que se reclama del otro, entre lo que se atesora acá y lo que se propugna desde allá; vale la pena ponderar lo que estimamos, a veces de modo entrañable en el mercado interno, y lo que exigen, sin vuelta de página, los vientos cosmopolitas. Vale la pena dar cuenta de lo que, no en vano, los teóricos del conflicto han señalado, es decir, que en el terreno de toda negociación no hay ganancias ni pérdidas absolutas o, lo que es lo mismo, que todo avance propio supone una concesión al otro y viceversa.

\section{Bibliografía}

Baudrillard, J. (1990). A transparencia do mal. Campinas: Papirus.

Baudrillard, J. (1981). De la seducción. Madrid: Cátedra.

Bloom, H. (1997). El canon occidental. Barcelona: Anagrama.

Borges, J. L. (1999). Borges verbal. Buenos Aires: Emecé.

Bourdieu, P. (1991). La distinción. Criterios y bases sociales del gusto. Madrid: Taurus.

Calinescu, M. (2003). Cinco caras de la modernidad. Modernismo, vanguardia, decadencia, kitsch, posmodernismo. Madrid: Tecnos.

Canetti, E. (1987). Masa y poder. Madrid: Alianza. 
Clifford, J. (1998). A experiencia etnográfica. Antropología e literatura no século $X X$. Río de Janeiro: UFRJ.

Elias, N. (2011). El proceso de la civilización. Investigaciones sociogenéticas y psicogenéticas. México: Fondo de Cultura Económica.

Foucault, M. (1993). Esto no es una pipa. Barcelona: Anagrama.

Foucault, M. (1976). Vigilar y castigar. México: Siglo XXI.

Freud, S. (1973). Tres ensayos sobre teoría sexual. Madrid: Alianza.

Fuentes, C. (1992). El espejo enterrado. México: Fondo de Cultura Económica.

Geertz, C. (2005). La interpretación de las culturas. Barcelona: Gedisa.

Goffman, E. (2004). La presentación de la persona en la vida cotidiana. Buenos Aires: Amorrortu.

Goffman, E. (1990). Los momentos y sus hombres. Barcelona: Paidós.

Goytisolo, J. (2007). Ensayos escogidos. México: Fondo de Cultura Económica.
Hall, E. T. (1971). La dimensión cachée. París: Seuil.

Hevia, J. (2008). ¡Habla, jugador! Gajes y oficios de la jerga peruana. Lima: Santillana.

Jakobson, R. (1975). Ensayos de lingüística general. Barcelona: Seix Barral.

Jameson, F. (1995) Espaco e imagen. Teorias do Pós-Moderno e outros ensaios. Río de Janeiro: Universidad Federal de Río de Janeiro.

Lévi-Strauss, C. (2009). El pensamiento salvaje. México: Fondo de Cultura Económica.

Lévi-Strauss, C. (2000). Raza y cultura. Madrid: Cátedra.

Lipovetsky, G. (1995). La era del vacío. Ensayos sobre el individualismo contemporáneo. Barcelona: Anagrama.

Nietzsche, F. (1994). Genealogía de la moral. Madrid: Alianza.

Vargas Llosa, M. (1996). La utopía arcaica. José María Arguedas y las ficciones del indigenismo. México: Fondo de Cultura Económica. 